\title{
Research on Non-stopping Toll System for Highway Based on the Modern Internet Payment Technology
}

\author{
Fengyi Rong ${ }^{1}$,Xiaoxu Chen ${ }^{1}$,Canran $\mathrm{Li}^{1}$,Yaning Shen ${ }^{1}$, Peirui Wang ${ }^{1}$ \\ ${ }^{1}$ Harbin Institute of Technology, school of Automotive Engineering, Harbin, China
}

\begin{abstract}
Keywords: new electronic non-stopping toll; Internet payment technology; license plate recognition technology; lane control technology; software development simulation

Abstract. In recent years, highway congestion is becoming our concerned topic, and the toll-speed congestion problems are most important cause of the congestion and the biggest obstacle to the promotion of the quality of highway service. In this regard, we propose a payment technology with non-stopping toll system which based on modern online payment technology. This work relies on the modern online payment platform, license plate recognition technology, lane control technology. Develop an application software, the highway users use computer or mobile phones before setting out paying tolls for the upcoming road trip (ticket purchase system similar to 12306) and enter the vehicle license plate information, the system will automatically send information to the ETC lane highway entrance controlled machine along the way, when the vehicle get into the lane through ETC at high speed, license plate recognition facility identifies the license plate, lane controller identifies the payment of the vehicle and controls the vehicle traffic, in order to achieve non-stopping toll.
\end{abstract}

\section{Introduction}

Background.With the rapid development of the domestic highway network, highway provides a more convenient and fast access conditions for travelers. At present, toll charging system is divided into two categories: labor costs (MTC) and electronic toll collection mode (ETC). And the labor costs is a less efficient way, which require motor vehicle park to receive the card when go through the toll station entrance, and must stop to pay credit card when go through the toll exit, when the vehicle reaches a certain level through traffic toll station, it will cause serious traffic congestion and vehicle delay in toll station entrances, causing noise and increase fuel consumption, emissions and other issues. ${ }^{[1-3]}$ The ETC although alleviate congested effectively in highway toll stations, saving the cost of highway operating, reducing the area for toll stations, reducing environmental pollution and other issues. But the application need longer time and the process of handling are more complex, users need to purchase and install an onboard unit (on board unit.OBU), also need to apply for special card bundled with it,and store a certain amount of advances in Cary, for groups of users who do not often use the highway, it doesn' t have enough attraction in our country . ETC toll collection system also faced undesirable bad and fraud problems such as take over cards, change the card, charged vehicles use free cards, large vehicles use the card for small vehicles. ${ }^{[4-6]}$ Therefore, under the current circumstances of China, due to the imperfect national credit system and the system of highway toll, the ETC toll application technology encountered great difficulties in China.

Research Status.Number plates under different lighting conditions can be identified by the HD camera to shoot pictures out, vehicle have no need tu be equipped with additional equipment, and the existing toll stations basically have HD camera monitoring system. License plate recognition rate has reached more than $95 \%$, and the time to identify is controlled within one second.

Development of lane control system is quite mature and has been widely used in ETC, various parking lots. ${ }^{[7-8]}$

Existing network payment platform already have a very large scale, the corresponding technology are matured, online payment has become a major payment channels, it's a convenient means of payment and populared by the majority of people of all ages.

License plate recognition technology has matured and lane control technology provides the basic application conditions, network technology provides the basic conditions of payment. 
Investigation and Analysis. In order to investigate the opinion for new electronic non-stopping toll, we did a survey. 88 people participated in our survey, male 45, female 43 people. Statistical results shown in Table 1.

Table 1 survey data

\begin{tabular}{ccccc}
\hline Age & $\begin{array}{c}\text { Support Online } \\
\text { shopping }\end{array}$ & ETC usage & $\begin{array}{c}\text { Frequent access } \\
\text { to high-speed }\end{array}$ & $\begin{array}{c}\text { Thenew system } \\
\text { Expected rate }\end{array}$ \\
\hline $15-25$ & $97.40 \%$ & $31.60 \%$ & $26.30 \%$ & $94.70 \%$ \\
$25-35$ & $100 \%$ & $43.80 \%$ & $34.40 \%$ & $96.90 \%$ \\
$>35$ & $91.30 \%$ & $56.50 \%$ & $82.60 \%$ & $91.30 \%$ \\
\hline
\end{tabular}

In all age groups, we are optimistic for online payment that provides a convenient way of online payment for our lives. Also of note are that all ages of people hold positive attitude to new electronic non-stopping toll based on payment online, thinking it will bring convenience to their high-speed traffic. Thus, the online payment technology is almost universal, has laid a good foundation to carry out this work.

\section{Design Principles}

Design Ideas.This work provides a new mode of non-stopping toll. The overall design concept is relying on the existing license plate recognition technology and online payment technology, make a development of a highway toll sites and corresponding phone APP. Highway toll server as a central processing platform, accepts and feedbacks from the system operation. Users can pay highway tolls safely through the online payment platform and using license plate recognition technology and lane control technology manage the traffic of paid vehicles. Namely by simplifying the payment link, and effective controlling of vehicle access, and ultimately achieve quick and easy non-stopping toll purposes.

Software Development.Taking full account of routable for the driver when traveling, design the algorithm model, the goals of which is to select and optimize "travel and transit services", the platform of which is geographic information system. The algorithm model uses component development mode on the web page and develops speed travel ticketing system based network payment technology. It implements the function of searching information (including keywords blurred, station inquiry, station to station inquiry, transit station inquiry), the real-time link and display between query information and map, fast pament, the way of obtaining invoices, feedbacking query result, automatically upgrading and maintaining the background data. This work fully reflects the "people-oriented and convenient" design philosophy.

Key Technology.A searching algorithm model based on traffic needs: This work is in full consideration of the uncertainty of the driver's travel behavior, establish a flexible algorithm model to achieve a variety of queries, and query results are optimized by different factors, provide the driver with travel program of the different needs, for example, shorter travel time, shorter travel distance or less travel expenses. Thus meet the travel needs of the driver's query uttemostly.

An interactive interfaces between web and charges software server: This work achieves a good combination between web and back-office application software, built IIS operating environment in the development process, using ASP.NET technology and code separation technology, is conducive to the development of pre- code development and post code data maintenance, ensuring the real-time accuracy of the two-way information. Complete interactive feedback and achieve the integration of traffic tickets through judging vehicle information.

Software architecture design with scalable function:The system uses the foreground about page of text and graphics, background applications and databases maintain comprehensive information processing system architecture, and it can be conveniently carried out in accordance with the driver's various needs. The system can be improved on this basis, that is not limited high-speed passenger mode ,that can also be combined aviation, shipping, rail passenger transport, to achieve an integrated multi-modal transport and better meet the diverse needs. 
Comprehensive back-end database processing and maintenance support information technology systems: In the Visual Studio environment, we make the choice of VB language programming, using Web Forms technology in ASP.NET, Web services technology, code-separation technology, data binding technology, database access, data list control application technology, which can help us developing a powerful rich graphical web under IIS environment.

\section{Run mode}

Work Process.Based on the above software development our work puts forward the high-speed road non-stopping toll mode, the core workflow of which is as follows.

(1)The user applies registered user name and through login online, fill in the license plate number and highway access information to complete the payment.

(2)Highway toll servers accept the message and generate orders.

(3)The charge server transmits the order information to the ETC lane control computer on the corresponding toll.

(4)The vehicles run into the entry of the toll station and the license plate recognition device sends the license plate information to the lane control system. And then the lane control system send the message to the charging server, and compare to the license plate information, and send the compared information to the lane control computer.

(5)If the license plate information in the order database and the lane control computer in entrance are inconsistent, then converted to manual toll lane, or continue step.

(6)Rise the open-lower railing on the control of lane controller, high-speed vehicular traffic and vehicles run into high-speed.

(7)When are driven out high-speed, vehicles still should be jugged the consistent of the vehicle license plate information and order data through the lane control computer in entrance by license plate recognition technology. If so, then release the vehicles, or prompts into manual toll lanes.

Overall system structure.This work is mainly adopts the following technical solution: inclouding freeway payment system in which users pays for themselves through the online payment platform, non-stopping toll control system and invoice printing system. Freeway payment system is composed by the user terminal, highway charge server and online payment server. Non-stopping toll lane control system is composed by lane control computer, license plate recognition device and lane peripheral devices. Invoice printing system includes independent receipt printer, artificial invoice printer and artificial Mailing.

\section{System Design}

Freeway payment system.System functions: User terminal includes the user's computer, mobile phones and other terminals which have networked payment function. Highway charge server is a computer cluster, which is through the Internet connected to the user terminal connected and online payment server, which is through the internal network connect to lane control computer and the invoice printing computer. Online payment server can be a online banking server or a third-party online bank payment platform server, which is through the Internet connect to the user terminal and highway charge server.

Cites registered:Users log in through a computer or mobile terminal, before logging we should register. The home page is shown in figure 2: Open registration page on the website, enter your user name, the system calls the user name of the database to determine if the user name is repeated, if repeated, the name is not available, users need to change the user name. If not repeated, the name is available and the user enters a password, and enter the code, read the highway toll web service protocols, submit agreement and an application for registration. Enter and fill in the details page, enter the name, sex, ID number, mailbox number or cell phone number and other informations, select the real-name system certification, the system determines whether the names and ID numbers match, if match, the registration is successful, if not match, then re-enter the details. 
Payment Order Online: After the successfully registered on line, we can use the user name and password to log in for online payment, fill out the information about the license plate number you want to pay and choose whether to send an invoice. If invoice is needed, enter the mailing address and contacted information, if invoice is not needed, you can enter directly to choose the pay type. If you choose to prepay, enter the amount paid; if you choose a single order, you need to select the date, the name of the entry toll station and exit toll station name, the system calculate costs according to the entry toll station and exit toll station .Users submit an order to enter the online payment page for payment. They can use the online banking or other third-party payment platform, for example, Alipay payment software to pay .If the payment is not successful, the order information can not generate; if the payment is successful, the system generates order information, and saved it to the database.

Lane Control System.System Function: Non-stopping toll control system, including the lane control computer, license plate recognition devices and lane peripherals, used to achieve the access management for the paid vehicle.

The lane control computer use IPC or embedded computer, package the license plate recognition device recognizes license plate information and sent to the highway toll server, the highway toll server compare license plate information, and sent the results to the lane control computer .Lane control computer control peripheral equipment, so it can control the opening and closing of the lane. License plate recognition device is consisted of the video surveillance with license plate recognition function and the router which is responsible for the information conveyor, license plate recognition device convey the recognized license plate information to the lane control computer. Lane peripherals, including elevator railings, lights, road side displays, alarms. They complete the release or stop of the vehicle by accepting the instruction of lane control computer.

Non-stopping toll for traffic:Vehicles reach the entrance of the toll, passing by the non-stopping road, license plate recognition device identifies plate information, transfers the license plate information to a computer lane control, lane control computer transfers the license plate information to a highway toll server, the server calls the database server and the license plate information for comparison, if the information does not comply with the order or does not contain advances, then send the results to the control computer traffic lane, lane control computer instructs the control lane peripherals, lift lever is not raised, the traffic signal is displayed in red, information boards show "Please turn manual toll lane"; if the information complies with the order or contains advances , then issue commands to control the lane control computer peripheral equipment, lift lever will rise, the traffic signal is green, information boards display the order or account balance, vehicle is released.

When the vehicle passes the exit of the toll station, passing by the non-stopping road, license plate recognition device identifies plate information, transfers the license plate information to a computer lane control, lane control computer transfers the license plate information to a highway toll server,the server calls the database server and the license plate information for comparison, if the order does not meet the information or is insufficient to cover the payment, the lane control computer sends instructions to the lane peripherals, suggesting the vehicle shift to the manual toll lane; if the information complies with the order or the prepayment is more than the tolls, the traffic lane control the calculator to deduct the toll. And issuing instructions to the lane peripherals, lift lever will rise, the traffic signal is green, information boards display the order or account balance, vehicle is released.

Invoice Printing System.System Function: Invoice printing systems, including self-printed invoices machines, artificial print invoices machines and artificial post. Users can print invoices through self-machine to print invoices, print invoices artificial, or get an invoice by mail.

Artificial invoice printing terminals and self-service printing terminal are consist of invoice receipt printer, monitor, keyboard and communication equipment components, connected to the highway toll through an internal network and the server. Invoice printing terminals arranged in motorway service areas, toll station and parking place and so on, users can access to invoices facilitatly.

Self / artificial invoice printing: If you choose manual printing, users can print invoices in hand window carrying valid identity documents, ordering information or providing user account information, and the staff making the some operation, such as order information or account 
information on the terminals, transfer information to the server in highway and then check the information, if they meet, print invoices, if not meet, you cannot print the invoice.

If you choose to print invoices yourself, the user enters order information or account information by keyboard in the self-invoice printing terminal , self-invoice printing terminal send information to be checked in highway toll, if the order information meet, then print the invoice, if not meet, You cannot print the invoice.

Mailing Invoices: If you choose the way to mail invoice, users should indicate whether you mail when you fill orders on the Internet. If you need to mail, then complete mailing address information. When this order is consumed, the consumer has been converted to an order, toll invoice information is transmitted to the artificial server from the toll highway and this order receipt printer, print invoices and invoice staff post.

\section{Conclusion}

Conventional non-stopping toll system is developed when the smart phones and network technology under undevelopment resulting high application costs and fees inconvenience, severely restricted the widespread use of the system. The system is a comprehensive analysis of the advantages and disadvantages of the existing charging system, new non-stopping toll system presents on the base of rapidly development and wide spread of Internet-based technology.

The system relies on the development of license plate recognition technology, online payment technology and lane control technology, so that pay highway tolls is extremely convenient, users only need to have a network payment terminals (mobile phone, telephone, computer, etc.) without having to purchase additional equipment, namely Payment can be achieved, and can use ETC lane.

Highway non-stopping toll system basing on modern highway network Payment technology makes payments more convenient, saving costs of ETC users; The proposed non-stopping toll system don' t need additional facilities on the highway, the implementation cost is low; system capital Billing is convenience; users have a convenient way to get the invoice from wide channels.

\section{References}

[1] Tong Yan, Jingpeng $\mathrm{Wu}, \mathrm{Yi}$ Duanzuo:submitted to Journal of China Electronic Business.Vol.5,No.10(2009), p.38-40.(in Chinese)

[2] Yang Liu.The research of non-stopping toll system for highway in intelligent transportation systems[D].Dalian:Dalian Maritime University.College of Transport 2004.

[3] Zhihui Chen.The research of license plate recognition technology under complex background[D].Taiyuan:Taiyuan University of Technology,College of Transport ,2014.

[4] Peng Fei.The research of highway toll lane system technology to control critical applied[D].Harbin:Harbin Engineering University,College of Transport,2010.

[5] Kun Bie.submitted to Journal of InternetWeek.No.1(2011), p.40-41.(in Chinese)

[6] Xiaojing Wang,et al.Electronic toll collection technology and engineering[M].Beijing China Communications Press,2006,8.

[7] Weiwei Wang.The mobile GPS applied research and system implementation[D].Jiangsu:Master's degree thesis of Jiangsu University.2008.

[8] Yaobo Liu, Yan Hu, Qi Ma.Platform applications and development of Winows Mobile[M].Beijing:Modern Posts and Telecommunications Press,2006. 